\title{
Long term follow up of premature infants: detection of strabismus, amblyopia, and refractive
} errors

\author{
Nicoline E Schalij-Delfos, Mieke E L de Graaf, Willem F Treffers, J Engel, Bernard P Cats
}

\begin{abstract}
Aim-To establish recommendations for long term ophthalmological follow up of prematurely born infants.

Methods-130 infants with a gestational age (GA) <37 weeks and born between 1 November 1989 and 31 October 1990 were enrolled in a prospective study about the development of strabismus, amblyopia, and refractive errors. Infants were subdivided in three groups according to GA: A $<28$ weeks $(\mathrm{n}=32), \mathrm{B} \geqslant 28-\leqslant 32$ weeks $(n=64), C>32-<37$ weeks $(n=34)$. Ophthalmological assessment took place at the postconceptional age of 32 weeks, at term and at $3,6,12$, and 30 months post term. At the age of 5 years parents received a questionnaire and a majority of the children was examined again $(n=99)$.
\end{abstract}

Results-At the age of 5 years 46 infants were known to have strabismus $(n=29)$ and/or amblyopia $(n=22)$ and/or refractive errors $(n=22)$. Statistical analysis showed that gestational age, duration of supplementary oxygen, and duration of hospitalisation were important predictive variables for the development of strabismus, amblyopia, or refractive errors $(\mathrm{SAR})$ at the age of 5 years $(p<0.05)$. Infants with a $\mathbf{G A} \leqslant 32$ weeks had a significantly higher risk of developing SAR than infants with a GA > 32 weeks, who developed an incidence comparable with the normal population. Strabismus developed mainly in the first year of life and at the age of 5 years. Most infants with amblyopia were detected at the age of 2-3 years. Refractive errors were found in the first year of life and at the age of 2.5 and 5 years.

Conclusion-Infants with a GA $<32$ weeks should be selected for long term ophthalmological follow up. These infants should be screened at the age of 1 year, in the third year of life (preferably at 30 months), and just before school age (including testing of visual acuity with optotypes).

(Br F Ophthalmol 2000;84:963-967)

Prematurely born infants are known to have an increased risk of developing ophthalmological problems. While retinopathy of prematurity (ROP) is the main problem in the neonatal period, strabismus, amblyopia, refractive errors, and visual impairment may develop later in life. While ample literature exists on screening for $\mathrm{ROP}^{1-4}$ very little has been written about screening programmes for long term follow up of premature infants. ${ }^{5-7}$ We performed a prospective study concerning the incidence and time of detection of strabismus, amblyopia, and refractive errors in a group of prematurely born infants to determine if uniform screening advice for long term follow up could be given.

\section{Patients and methods}

\section{STUDY POPULATION}

The study population consisted of 130 infants (gestational age $<37$ weeks) born between 1 November 1989 and 31 October 1990 and admitted to the Wilhelmina Children's Hospital. Infants with a gestational age $\leqslant 32$ weeks and/or a birth weight $<1500 \mathrm{~g}$ were screened for ROP from their fifth week of life onwards, according to our protocol. ${ }^{8}$ Parents of these infants were asked for permission to include their child in the study. Infants were subdivided into three groups according to gestational age (GA): group A $<28$ weeks; group B $\geqslant 28-\leqslant 32$ weeks; group $\mathrm{C}>32-<37$ weeks. Infants from group $\mathrm{C}$ were selected at random from the level II department of our hospital.

General data concerning the neonatal period were assembled. At the postconceptional age of 32 weeks, at term and at 3, 6, 12, and 30 months post term all infants were examined by an ophthalmologist and a neonatologist. Apart from this, examinations were done at any time when the parents or attending physicians/ paediatricians suspected the development of ocular abnormalities. At the age of 5 years parents received a questionnaire on general health, general performance, and ophthalmological problems of their children, and most of the children were examined again.

OPHTHALMOLOGICAL EXAMINATIONS

Ophthalmological examinations included an orthoptic examination for the detection of strabismus, amblyopia, and refractive errors. Ophthalmoscopy was performed at every examination. Strabismus was defined as a latent symptomatic or a manifest squint. ${ }^{9}$ Amblyopia was considered to be present when patients were treated as such, when a difference in visual acuity between the two eyes of more than two lines existed, in case of unilateral strabismus or resistance to occlusion of one eye. ${ }^{10}$ Cycloplegic refraction was performed with streak retinoscopy after instillation of cyclopentolate $0.5 \%$ eyedrops, twice at a 10 minute interval, 30 minutes before examination. Refractive values were converted to spherical equivalents and astigmatism was 
Table 1 General characteristics of population (SD) arranged according to different age groups

\begin{tabular}{|c|c|c|c|c|c|}
\hline & $\begin{array}{l}\text { Group } A \\
\text { GA }<28 \text { weeks }\end{array}$ & $\begin{array}{l}\text { Group } B \\
\text { GA } \geqslant 28, \\
\leqslant 32 \text { weeks }\end{array}$ & $\begin{array}{l}\text { Group } C \\
\text { GA }>32, \\
<37 \text { weeks }\end{array}$ & $p$ Values & $\begin{array}{l}\text { Differences } \\
\text { between groups }\end{array}$ \\
\hline No & 32 & 64 & 34 & & \\
\hline Mean gestational age (weeks) & $26.9(0.8)$ & $29.9(1.0)$ & $34.4(1.2)$ & $<0.00$ & A-B-C \\
\hline Mean birth weight $(\mathrm{g})$ & $936(144)$ & $1305(298)$ & 2089 (438) & $<0.00$ & A-B-C \\
\hline Artificial ventilation (days) & $18.6(12.7)$ & $7.1(9.4)$ & $0.2(0.8)$ & $<0.00$ & A-B-C \\
\hline Supplemental $\mathrm{O}_{2}$ (days) & $45.8(35.8)$ & $37.9(85.2)$ & $0.3(0.8)$ & $<0.00$ & $(\mathrm{~A}=\mathrm{B})-\mathrm{C}$ \\
\hline Mean maximum $\mathrm{O}_{2}$ administration (\%) & $67.4(28.2)$ & $66.2(32.3)$ & $22.2(3.0)$ & $<0.00$ & $(\mathrm{~A}=\mathrm{B})-\mathrm{C}$ \\
\hline Mean duration of hospitalisation (days) & $71.1(37.8)$ & $54.2(60.1)$ & $22.3(9.4)$ & $<0.00$ & $(\mathrm{~A}=\mathrm{B})-\mathrm{C}$ \\
\hline $\mathrm{BPD}(\mathrm{N}(\%))$ & $16(50 \%)$ & $19(29.7 \%)$ & 0 & $<0.1$ & $(\mathrm{~A}=\mathrm{B})-\mathrm{C}$ \\
\hline PDA (N (\%)) & $14(43.8 \%)$ & $13(20.3 \%)$ & 0 & $<0.02$ & A-B-C \\
\hline $\operatorname{ROP}(\mathrm{N}(\%))$ & $21(65.6 \%)$ & $12(18.7 \%)$ & 0 & $<0.00$ & $\mathrm{~A}-\mathrm{B}-\mathrm{C}$ \\
\hline
\end{tabular}

Continuous variables were tested by ANOVA on class differences and $\mathrm{p}$ values are listed in column 5 . A Tukey post hoc procedure was performed to determine which age groups are really different from each other. A $\chi^{2}$ test was performed on discrete variables Bronchopulmonary dysplasia (BPD), persistent ductus arteriosus (PDA), retinopathy of prematurity (ROP) of groups A and B.

documented. Children were considered to have a significant refractive error in case of hypermetropia $>3$ dioptres (D), myopia $>3 \mathrm{D}$, astigmatism $>1 \mathrm{D}$, and/or anisometropia $>1.5 \mathrm{D} .^{6}{ }^{11}$

\section{STATISTICAL ANALYSIS}

General clinical data were evaluated by using the Student's $t$ or $\chi^{2}$ test for discrete variables and a one way analysis of variance (ANOVA) for continuous variables. If the ANOVA test resulted into significance, a Tukey post hoc procedure was performed. Differences with a $\mathrm{p}$ value $<0.05$ were considered significant. To assess the effect of different variables on the development of ocular sequelae at the age of 5 years, a logistic regression analysis (LRA) as well as a classification and regression trees (CART) technique was used. The predictive variables were selected for inclusion in the LRA model if they were significant at the $5 \%$ level when tested by $t$ test.

\section{Results}

General characteristics of the population are given in Table 1 . The three age groups A, B, and $\mathrm{C}$ showed significant differences for mean gestational age, mean birth weight (BW), number of days of artificial ventilation, persistent ductus arteriosus (PDA), and retinopathy of prematurity (ROP). With regard to the number of days with supplemental oxygen administration, mean maximum concentration of supplementary oxygen, mean duration of hospitalisation and bronchopulmonary dysplasia (BPD), group A and B were comparable but they were significantly different from group C. Retinopathy of prematurity (ROP) was found in 33 infants: group A: 21 (stage 1 in 12 eyes, stage 2 in 22 eyes, and stage 3 in four eyes), group B: 12 (stage 1 in eight eyes, stage 2 in 14 eyes, and stage 3 in 10 eyes), group C: 0 . No ROP stage 4 or more was found. Two

Table 2 Number and percentage of infants with strabismus, amblyopia, and refractive errors at the age of 5 years

\begin{tabular}{lllll}
\hline & All infants & Group A & Group B & Group C \\
\hline No & 99 & 28 & 51 & 20 \\
SAR & $46(46 \%)$ & $16(57 \%)$ & $28(55 \%)$ & $2(10 \%)$ \\
Strabismus & $29(22 \%)$ & $11(39 \%)$ & $17(33 \%)$ & $1(5 \%)$ \\
Amblyopia & $22(17 \%)$ & $9(32 \%)$ & $11(22 \%)$ & $2(10 \%)$ \\
Refractive errors & $22(17 \%)$ & $8(29 \%)$ & $13(25 \%)$ & $1(5 \%)$ \\
\hline
\end{tabular}

$\mathrm{SAR}=$ number of patients with strabismus and/or amblyopia and/or refractive errors. patients in group B underwent cryotherapy because they reached threshold disease as defined by the Cryotherapy for ROP Cooperative Group. ${ }^{12}$

The questionnaire, sent at the age of 5 years, was returned by parents of 99 infants. All infants had an ophthalmological examination at the age of 5 years, either at the hospital by an ophthalmologist $(n=61)$ and/or at the child health clinics by a general physician $(n=38)$. During the study period two infants died, 11 infants moved without a forwarding address, and 18 questionnaires were not returned because parents were not motivated to do so as they or the health clinic physician observed no problems (verbal communication with the parents).

At the age of 5 years 46 infants were known to have strabismus $(n=29)$ and/or amblyopia $(n=22)$ and/or refractive errors $(n=22)(S A R)$. Thirteen infants wore spectacles. A division according to age groups is given in Table 2. A $t$ test analysis showed that infants in groups A and $B$ had a significantly higher risk of developing SAR than infants in group $\mathrm{C}(t$ test $A B: p=0.8$; AC: $p<0.00$; $B C: p<0.00)$. In an earlier study, data of the infants from groups A and $\mathrm{B}$ with and without ROP in the neonatal period were compared. ${ }^{13}$ Infants with ROP were found to have more strabismus $(\mathrm{p}=0.002)$, amblyopia $(\mathrm{p}<0.001)$, myopia $(p=0.003)$, and glasses $(p=0.001)$ at the age of 5 years than infants without ROP.

In a logistic regression gestational age $(p=0.005)$, duration of oxygen supplementation $(\mathrm{p}<0.000)$, and duration of hospitalisation $(p=0.003)$ turned out to be important predictive variables for the development of strabismus, amblyopia, or refractive errors at the age of 5 years. Gestational age $(p=0.003)$ and the number of days of artificial ventilation $(p<0.000)$ were found to be predictive variables for the development of ROP. There is a strong relation between the development of ROP in the neonatal period and the development of ophthalmological sequelae at the age of 5 years if these are tested by LRA separately $(\mathrm{p}=0.009)$. However, performing an LRA on all variables, other variables than ROP have a stronger effect. This can be explained by the variable gestational age, which has a strong effect on both ROP and ophthalmological problems at the age of 5 years. 


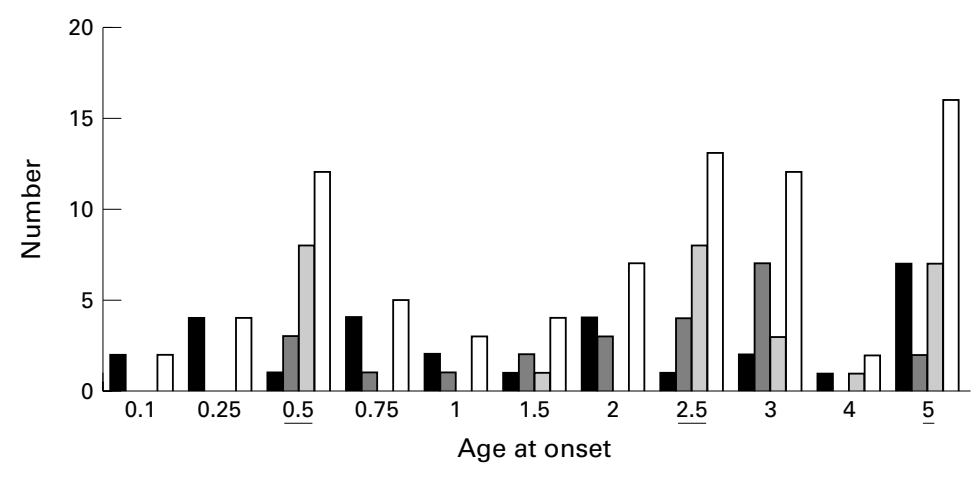

Gtrabismus $\square$ Amblyopia $\square$ Refractive error $\square$ Overall

Figure 1 Age at onset of strabismus, amblyopia, and refractive errors of infants who had been classified as having ophthalmological abnormalities at the age of 5 years. The ages at which follow up examinations were originally scheduled are underlined.

In addition to the evaluation of factors influencing the development of strabismus, amblyopia, and refractive errors attention was given to the mean age of detection and course in time. The mean age of detection was 2.1 years (SD 1.8, range 0.1-5.0) for strabismus and 2.3 years (1.2, range 0.5-5.0) for amblyopia. Spectacles were prescribed at a mean age of 3.0 years $(0.9$, range $1.5-5.0)$. Evaluating the data over time (Fig 1) strabismus developed mainly in the first year of life and around the age of 5 years. All cases of strabismus that developed before the age of 1 year presented with large angle esotropias or exotropias; most infants who developed strabismus around the age of 5 had decompensating heterophorias. Infants who developed amblyopia in the first year of life all had strabismus; however, most cases of amblyopia were detected at the age of 2-3 years. Refractive errors were detected in about equal amounts at any scheduled follow up examination - that is, at the corrected age of 6 months, 2.5, and 5 years. Infants who were examined at the age of 3 had not attended for their planned check up at the age of 2.5 years.

Furthermore, Figure 2 shows that if only infants with a gestational age $\leqslant 31$ weeks had

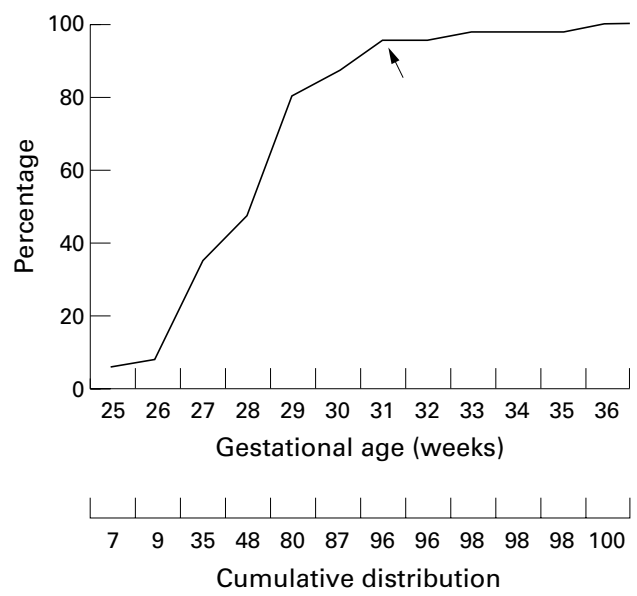

Figure 2 Cumulative distribution of infants with ocular abnormalities (strabismus, amblyopia, and/or refractive errors) at the age of 5 years, according to gestational age at birth. If only infants with a gestational age $\leqslant 31$ or $\leqslant 32$ weeks had been screened, $96 \%$ of infants with

ophthalmological abnormalities would have been detected. been screened, $96 \%$ of infants with ophthalmological sequelae would have been detected in this study.

\section{Discussion}

In this prospective study of prematurely born infants a high incidence of strabismus, amblyopia, and refractive errors was found, grossly comparable with other studies. Forty six per cent of the infants did have some visual abnormality. Strabismus was found in $29 \%$, amblyopia and refractive errors were found in $22 \%$ of cases.

In a population based study on 313 very low birth weight (VLBW) infants $(<1500 \mathrm{~g})$ at the age of 7-8 years Darlow et al found an overall ophthalmological morbidity of $64 \%$, strabismus in $29 \%$, myopia in $21 \%$, hypermetropia in $18 \%$, and astigmatism in $11 \%{ }^{14}$ These findings were supported by a study of Robinson and O'Keefe ${ }^{15}$ who examined 131 infants who had been screened for ROP in the neonatal period. They found myopia in $20 \%$ and strabismus in $22 \%$. Holström et $a l^{5}{ }^{6}$ followed 248 infants for 3.5 years and found increased incidences of myopia, astigmatism, anisometropia, and strabismus compared with control groups of full term children. In an earlier study we also found a significantly higher risk of developing strabismus $(20 \%)$ and myopia $(22 \%)$ in 96 infants with a gestational age $\leqslant 32$ weeks. ${ }^{13}$ All studies had in common that infants who developed any stage of ROP in the neonatal period were found to have a significantly higher risk of developing strabismus or myopia than infants without ROP. Pennefather et $a l^{16}$ studied 565 infants with gestational age $<32$ weeks at the age of 2-3 years retrospectively and found high incidences of abnormalitiesstrabismus in $12.5 \%$ and refractive errors in $12.7 \%$. These studies all compare their outcomes of ocular morbidity with incidence figures of full term neonates and conclude that prematurity is associated with an increased risk to develop ophthalmological problems. However prematurity is defined as being born with a gestational age $<37$ weeks. When searching for criteria for patient selection for ophthalmological screening one has to be sure that neonates with GA $>32-<37$ weeks have incidences comparable with the normal population. Therefore this study differs from previous reports in that premature infants $>32-<37$ weeks (group C) were included. Infants from group C indeed had a significantly lower risk of developing ocular problems than infants from groups $\mathrm{A}$ and $\mathrm{B}$.

Statistical analysis of the data showed that gestational age, duration of supplementary oxygen, and duration of hospitalisation were important predictive variables for ocular morbidity in this cohort of prematures. It is possible to create a predictive model to calculate the probability for ophthalmological sequelae at the age of 5 years for every prematurely born infant. As this predictive model is difficult to handle in a clinical setting, it is presented as a note at the end of the article. For practical purposes GA is the most useful factor to use in developing selection criteria for long term 
follow up, as GA is reproducible by all parents for many years to come, whereas the duration of oxygen supplementation or hospitalisation are not. Figure 1 shows that when all infants with a GA $\leqslant 31$ weeks would have been screened, $96 \%$ of infants with ocular abnormalities would have been detected in this study. Incidence figures for strabismus (5\%), amblyopia (3\%), and refractive errors $(5 \%)$ of the normal population of preschool infants can be found in a report about supply and demand in the care of patients with eye disease in the Netherlands. ${ }^{17}$ This supports the idea that long term follow up of prematures with GA $\leqslant 31$ or $\leqslant 32$ weeks is sensible. To create a guideline that is easy to handle in practice, the advice for long term follow up could be combined with the advice for ROP screening in the neonatal period as most of these programmes, including the Dutch programme, screen infants of $<32$ weeks' gestation.

After the definition of a population for long term follow up, it is equally important to define advice for timing of screening. First of all, parents should be informed that their child is at risk of developing ophthalmological problems later in life. They should be encouraged to seek expert advice whenever they have doubts about the status of their infants' eyes. In the past many authors stressed the importance of long term follow up of prematurely born infants. However, few specify their advice. Pott et al indicated that the optimal age for the detection of strabismus in at-risk infants is at 9 months corrected age. Although they explained that children should be re-examined later on, they did not give further recommendations. Holmström et $a l^{5}{ }^{6}$ recommended that if only one examination could be done this should take place around the age of 1 year. If a second examination was planned this should be performed at the age of 24-30 months. A third examination should take place at 42 months of age (including testing of visual acuity with optotypes). Recommendations from the current study, for the time of follow up screening can be deduced from Figure 2. Strabismus and amblyopia developed in the first year of life, around the age of 2.5 and 5 years. Refractive errors were detected at the age of 6 months, $2.5,3$, and 5 years.

Combining the information from these three studies we suggest the following screening strategy: first examination at the corrected age of 1 year, a second examination in the third year of life (preferably at 30 months), and a third examination just before school age (in the Netherlands just before the age of 4) as visual acuity can be reliably measured at this age. Holmström states that when only one examination is feasible, infants should be screened at the age of 1 . However, this study shows that ophthalmological abnormalities are detected in about equal amounts every time infants are screened. This means that premature infants who are at risk of developing strabismus, amblyopia, and/or refractive errors should be screened more than once in their younger years.
Table 3 Long term follow up of prematurely born infants for the detection of strabismus, amblyopia, and refractive errors

Who? Infants with a gestational age $<32$ weeks

When? At the age of 1 year, 2.5 years, and just before school age

The increased survival of prematurely born infants poses a long term problem in terms of increased incidence of ophthalmological problems such as strabismus, amblyopia, and refractive errors. Patient selection and timing of follow up examinations should be formulated. The conclusion of this study is that infants with a gestational age $<32$ weeks should be selected for long term ophthalmological follow up. One has to keep in mind that infants with prolonged oxygen supplementation or hospitalisation as well as infants who developed ROP in the neonatal period or infants with neurological complications, ${ }^{18}{ }^{19}$ are at the highest risk. Parents should be made aware of the various problems their infants can encounter. Infants should be screened at the age of 1 year, in the third year of life (preferably at 30 months), and just before school age (including testing visual acuity with optotypes) (Table 3 ).

Note: Predictive model to calculate the probability for ophthalmological sequelae at the age of 5 years (p) with standard errors in parentheses: $\log (\mathrm{p} /(1-\mathrm{p}))=9.43(3.56)-$ 0.31 (0.11) $\mathrm{GA}+0.04(0.01) \mathrm{O}_{2} \mathrm{adm}-0.03$ (0.01) hosp

$\mathrm{GA}=$ gestational age; $\mathrm{O}_{2}$ adm $=$ duration of oxygen administration; hosp $=$ duration of hospitalisation.

1 Retinopathy of prematurity: guidelines for screening and treatment. The report of a joint working party of The Royal College of Ophthalmologists and The British Association of Perinatal Medicine. Early Hum Dev 1996;46:239-58.

2 Fledelius HC, Rosenberg T. Retinopathy of prematurity. Fledelius HC, Rosenberg T. Retinopathy of prematurity.
Where to set screening limits? Recommendations based on Where to set screening limits? Recommendations based on
two Danish surveys. Acta Paediatr Scand 1990;(Suppl) 210:63-5.

3 Darlow BA, Clemett RS. Retinopathy of prematurity: screening and optimal use of the ophthalmologist's time. Aust NZ F Ophthalmol 1990;18:41-6.

4 Schalij-Delfos NE, Zijlmans BLM, Wittebol-Post D, et al. Screening for retinopathy of prematurity: do former guidelines still apply? F Pediatr Ophthalmol Strabismus 1996;33: 35-8.

5 Holmström G, El Azazi M, Kugelberg U. Ophthalmological follow-up of preterm infants: a population based, prospective study of visual acuity and strabismus. $\mathrm{Br} \mathcal{F} O$ phthalmol 1999;83:143-50.

6 Holmström G, El Azazi M, Kugelberg U. Ophthalmological long term follow-up of preterm infants: a population based, prospective study of the refraction and its development. $\mathrm{Br}$ prospective study of the refraction

7 Pott JWR, van Hof-van Duin J, Heersema DJ, et al. Strabismus in very low birthweight and/or very preterm children: mus in very low birthweight and/or very preterm children:
discrepancy between age of onset and start of treatment. discrepancy between age of o

8 Schalij-Delfos NE, Zijlmans BLM, Cats BP. Towards a universal approach for screening of retinopathy of prematurity (ROP). Doc Ophthalmol 1996;92:137-44.

9 Mein J, Trimble R. Diagnosis and management of ocular motility disorders. 2nd ed. Oxford: Blackwell, 1991:25963.

10 Mein J, Trimble R. Diagnosis and management of ocular motility disorders. 2nd ed. Oxford: Blackwell, 1991:199211.

11 Edwards K, Llewellyn R. Optometry. London: Butterworth, 1988:184-5.

12 Palmer EA, Flynn JT, Hardy RJ, et al. Incidence and early course of retinopathy of prematurity. The Cryotherapy for Retinopathy of Prematurity Cooperative Group. OphthalRetinopathy of Prematurity
mology 1991;98:1628-40.

13 Schalij-Delfos NE, Cats BP. Long term visual outcome of premature eyes with and without retinopathy of prematurity. In: Reibaldi A, Di Pietro M, Scuderi A, et al, eds. Progress in retinopathy of prematurity. Amsterdam: Kugler Progress in retinot 
14 Darlow BA, Clemett RS, Horwood LJ, et al. Prospective study of New Zealand infants with birth weight less than $1500 \mathrm{~g}$ and screened for retinopathy of prematurity: visual outcom at age 7-8 years. Br F Ophthalmol 1997;81:935-40.

15 Robinson R, O'Keefe M. Follow-up study on premature infants with and without retinopathy of prematurity. $\mathrm{Br} \mathcal{F}$ Ophthalmol 1993;77:91-4

16 Pennefather PM, Clarke MP, Strong NP. Ocular outcome in children born before 32 weeks gestation. Eye 1995; 9(suppl):26-30.
17 Biesheuvel-Snellen FMM. Het oog wil ook wat. Thesis: Erasmus University Rotterdam, The Netherlands. Mijdrecht: Zyma Nederland 1990:21.

$18 \mathrm{De}$ Vries LS, Dubowitz LMS. Cystic leucomalacia in preterm infant: site of lesion in relation to prgnosis. Lancet 1985;ii:1075-6.

19 Eken P, van Nieuwenhuizen O, vd Graaf Y, et al. Relation between neonatal cranial ultrasound abnormalities and cerebral visual impairment in infancy. Dev Med Child Neurol 1994;36:3-1. 